\title{
Editorial policy: industry funding and editorial independence
}

$\mathrm{T}$ he separation of editorial decisions from financial issues is essential to ensure editorial independence. Given this, it is important to reflect upon current policy and practices with respect to advertising and supplement sponsorship. Consider, first, advertising. CMA policy is clear:

Editorial decisions are not influenced by advertising or sponsorship, and are made without consideration of the advertising or sponsorship scheduled to appear. Sponsors and advertisers will not determine specific editorial content or in any way influence editorial decision-making nor will they have the opportunity to review any material prior to publication. Advertisements and sponsorships will not be sold on condition that specific editorial content will be subsequently produced. Advertisements and sponsorships will not be accepted where the fact of the advertisement or sponsorship would raise an inference of influence on editorial content or decision-making, or of the Physician Services Group or CMA's endorsement of the sponsor or its products or services (www.cma.ca/index.cfm /ci_id/25274/la_id/I.htm).

In practice, $C M A J$ follows this policy and sponsors are kept unaware of editorial content prior to the publication of the issue in which their paid advertisement appears. Furthermore, CMAJ practice precludes advertisement placement near editorial content that could be construed in any way to be related to the advertising content. While there is currently no systematic regular review to assess the level of separation of advertising and editorial content, a quick scan of recent issues of $C M A J$ does not raise any red flags.

More troubling is the relationship between editorial content and the funding of supplements. CMAJ, like other peerreviewed editorially independent journals, publishes only peer-reviewed articles in its supplements. However, CMAJ looks to industry and other sponsors to cover the costs of publishing supplements. Groups who bring forward a proposal for a supplement are encouraged to work with $C M A J$ to find nonindustry sponsors if possible. Nonetheless, most supplements are funded by industry. Although CMAJ only indexes supplements that have at least one nonindustry sponsor, supplements with only industry sponsorship are still published.

According to CMA policy:

Although readers, sponsors and advertisers may be provided with $\widehat{m}$ general information about the content of an upcoming publication (e.g., ... supplements ...) specific details about the content are confidential until publication.

In practice, when a supplement is proposed, potential sponsors are informed of the theme and sometimes the article titles - a very different process than that used for the main journal. Therefore, in the case of supplements, industry has the opportunity to knowingly and selectively sponsor a supplement that may more directly relate to their product or product areas. This raises concerns about advertisement placement, influence on readers and the separation of advertising and editorial content in supplements, and these concerns are particularly acute since the breadth of advertisers for any given supplement is much narrower than those for the main journal.

Another concern that arises out of the supplement funding process is topic selection. Given the need for sponsorship funding to cover the publishing costs, only those supplements whose topics can attract industry or other outside funding are accepted for publication. Worthy areas proposed for a supplement that may indeed have great significance to the Canadian health care system are not published if they cannot attract enough funding. A few papers may eventually be printed in the Journal from such proposed supplements, but the more comprehensive, in-depth picture that the supplement structure offers is not an option. This is not a matter of quality but rather one of attractiveness to funders. Hence financial considerations indirectly influence supplement topic selection. This is a problem for $C M A J$ as well as for other general medical journals (www.cmaj.ca/pdfs/messagefromeditor.pdf).

Possible solutions for ensuring more independence of editorial content from advertising in supplements and a better approach to topic selection include: I) implementing a "surtax" on industry-sponsored supplements to help defray the costs of other nonsponsored supplements; 2) setting aside $0.5 \%-1 \%$ of $C M A J$ profits to support supplements in which there would be either no advertisements or only advertisements unrelated to the editorial content of the supplement; 3 ) asking the Canadian Institutes of Health Research to set up a quarterly competition for supplement funding (to which all health journals could apply) as part of their support for knowledge translation initiatives; or 4) asking Health Canada to establish a funding stream for supplement publication.

Resolution of these concerns with respect to editorial independence and supplements is difficult, as the issue is complex. But a resolution must be found - the current relationship with industry is too cozy.

\section{Noni MacDonald \\ Acting editor-in-chief \\ Jocelyn Downie \\ Advisor to the interim editorial board \\ CMAJ}

This editorial has been peer reviewed. 